\title{
Validation of the Face Name Associative Memory Exam in Cognitively Normal Older Individuals
}

\author{
Rebecca E. Amariglio a,b,c, ${ }^{\star}$, Katherine Frishe ${ }^{a}$, Lauren E. Olson ${ }^{a, b}$, Lauren P. Wadsworth ${ }^{b}$, \\ Natacha Lorius ${ }^{a, b}$, Reisa A. Sperling ${ }^{a, b, c}$, and Dorene M. Rentz ${ }^{a, b, c}$ \\ ${ }^{a}$ Center for Alzheimer Research and Treatment, Department of Neurology, Brigham and \\ Women's Hospital \\ bDepartment of Neurology, Massachusetts General Hospital \\ cHarvard Medical School
}

\begin{abstract}
The recently developed Face Name Associative Memory Exam (FNAME), a challenging paired associative learning task, shows promise in detecting the subtle cognitive changes characteristic of preclinical Alzheimer's disease. In this study, we evaluated the validity and reliability of the FNAME in 210 cognitively normal older individuals (58-90 years of age). Construct validity of the measure was assessed by principal components analysis, which revealed two independent factors. Correlations between the FNAME subtests and another episodic memory test were significant. The results indicated strong test-retest reliability in a subsample $(n=41)$. Normative data stratified by age were also generated.
\end{abstract}

\section{Keywords}

preclinical Alzheimer's disease; aging; neuropsychology; instrument validation

\section{Introduction}

\footnotetext{
With secondary prevention trials on the horizon, neuropsychologists are being called upon to develop new cognitive and functional instruments sensitive to preclinical Alzheimer's disease (AD). Most standardized neuropsychological (NP) tests are designed to detect cognitive deficits at the stage of Mild Cognitive Impairment (MCI) or AD dementia and may not be useful in uncovering the mild changes in cognition that precede these states. Indeed, a relationship between cognitive test performance and evidence of early AD pathology, namely amyloid- $\beta$ burden, has not typically been found in cognitively normal individuals (CN) using standard clinical neuropsychological tests (Aizenstein et al., 2008; Jack et al., 2008; Mormino et al., 2009; Storandt, Mintun, Head, \& Morris, 2009). In contrast, the use of challenging associative memory tasks has revealed a relationship between amyloid- $\beta$ accumulation and cognitive performance in $\mathrm{CN}$, suggesting their potential utility in early detection of AD (Rentz et al., 2011; Rentz et al., 2010). Further efforts to validate new, sensitive measures are needed, however, before they can be applied routinely in clinical trials.
}

\footnotetext{
*Corresponding Author: Rebecca E. Amariglio, PhD, Division of Cognitive and Behavioral Neurology, 221 Longwood Avenue, Boston, MA 02115, 617-732-8085 (telephone); 617-738-9122 (fax), ramariglio@ partners.org.
} 
It has been previously reported that paired associative learning (Fowler, Saling, Conway, Semple, \& Louis, 2002; Lindeboom, Schmand, Tulner, Walstra, \& Jonker, 2002; Parra et al., 2010), and in particular face-name associative memory (Werheid \& Clare, 2007), is sensitive to early AD related changes. Studies using face-name memory fMRI paradigms also suggest vulnerable associative memory in early $\mathrm{AD}$, manifesting as altered activation in memory networks reported in patients with a clinical diagnosis of mild $\mathrm{AD}, \mathrm{MCI}$ and even in genetically at-risk or amyloid-positive CN individuals (Celone et al., 2006; Miller et al., 2008; Quiroz et al., 2010; Sperling et al., 2003; Sperling et al., 2009). Based on fMRI findings, an offline face-name associative memory task was developed, which has shown a relationship between face-name retrieval and amyloid- $\beta$ deposition in frontal and parietal regions in cognitively normal older individuals (Rentz, et al., 2011).

In this context, we sought to validate the Face Name Associative Memory Exam (FNAME) developed by Rentz et al. (2011). Principal components analysis (PCA) was used to evaluate the construct validity and factor structure of the FNAME. Convergent validity was established between the FNAME and another measure of episodic memory, the 6-trial Selective Reminding Test (SRT) (Masur et al., 1989). Normative data was devised by age group. Ultimately, our goal was to validate the FNAME, as a means of honing a potential tool for the neuropsychological detection of preclinical AD.

\section{Methods}

\section{Subjects}

Two hundred and ten subjects enrolled in the Harvard Aging Brain Study at the Center for Alzheimer Research and Treatment at the Brigham and Women's Hospital (BWH) and Massachusetts General Hospital (MGH) were studied using protocols and informed consent procedures approved by the Partners Human Research Committee. Of note, 45 of the 210 subjects of our sample were previously reported (Rentz, et al., 2011).

Subjects were clinically normal (ages 58-90, mean $=73.57 \pm 6.73$ ), defined by a Clinical Dementia Rating (CDR) (Morris, 1993) score of 0, a Mini Mental State Exam (MMSE) (Folstein, Folstein, \& McHugh, 1975) score of greater than or equal to 27 and a Geriatric Depression Scale (GDS) score of less than 11 (Yesavage et al., 1983). There was no significant difference between the amount of men and women in the sample. A detailed review of medical history and functional performance as well as physical and neurological examinations confirmed their status as clinically normal $(\mathrm{CN})$. None of the participants had a history of alcoholism, drug abuse, head trauma or current serious medical or psychiatric illness.

\section{FNAME Procedure}

As described by Rentz et al. (2011), the FNAME requires the subject to remember 16 unfamiliar face-name (FN-N) pairs and 16 face-occupation (FN-O) pairs for a total of 32 cross-modal paired associates to be remembered. The administration procedure was designed to be similar to that of the Free and Cued Selective Reminding Test (Grober, Merling, Heimlich, \& Lipton, 1997) and the Memory Capacity Test (Buschke 2005, personal communication). The test was originally designed to have an initial learning phase as well as free recall and cued recall trials. However, after administering the FNAME to 148 subjects following the procedure outlined by Rentz et al. (2011), we reassessed the administration protocol to determine if the measure contained any redundant scores that could be removed. Specifically, we decided that the free recall condition was not a wellcontrolled paired associative task, as subjects were not required to match a name or occupation with a face. While in some cases subjects may have visualized the face in order 
to recall the name, we could not be certain of each subject's strategy for recall. Thus, we administered the FNAME to 62 subjects without immediate and delayed free recall to determine if cued recall performance was impacted. An independent samples t-test comparing subjects who were administered the two versions of the FNAME (with and without free recall) revealed no significant differences in performance on cued recall (CRN, CRN30, CRO, CRO30) (Table 1 about here), supporting the removal of the free recall subtests (FRN and FRN30) from the final version of the FNAME.

The final FNAME procedure was as follows: Initial Face Study Phase: The test begins with an exposure to all 16 faces. Subjects are shown 4 faces to a page, one face in each quadrant. They are asked to look at each face for a total of 2 seconds until they have seen all 16 faces. Initial Study of Face-Name Pairs (FN-N): Subjects are then presented the same 16 faces with names underneath and asked to study the name that goes with the face. Subjects are given only one exposure to learn all 16 FN-N pairs. Initial Cued Recall of Face-Name Pairs: The subjects are then shown the face and asked to recall the name that goes with the face. The correct number of FN-N pairs is recorded as an initial learning score for names (ILN).

Initial Study of Face-Occupation Pairs ( $F N-O$ ): Subjects are then shown the same faces but this time with occupations underneath. The FN-O pairs are presented in the same manner as the FN-N pairs until all 16 FN-O pairs are studied. Initial Cued Recall of Face-Occupation Pairs: Subjects are again shown the face and asked to recall the occupation that goes with the face. Correct recall of FN-O pairs is tabulated as initial learning of occupations (ILO).

Immediate Cued Recall: Following the Initial Cued Recall trial, subjects are shown the face and asked to recall the name (CRN) and occupation (CRO) that was associated with the face. 30-Minute Delayed Cued Recall: Subjects are again shown the face and asked to recall the name (CRN30) and occupation (CRO30) associated with the face.

\section{Neuropsychological (NP) evaluation}

In addition to the FNAME, subjects were administered an extensive battery of neuropsychological (NP) tests that covered the cognitive realms of attention, executive functions, memory language, and visuospatial processing. For this study we focused on an episodic memory test: 6-Trial Selective Reminding Test (SRT) (Masur, et al., 1989) and created a z-score composite of long-term retrieval (LTR), long-term store (LTS), continuous retrieval (CR), continuous long-term retrieval (CLTR), total recall (TR), delayed recall at 10-minutes (DR), and delayed recall at 30 minutes (DR30), based on a prior factor analysis (Rentz, et al., 2011).

\section{Validation Procedures}

The abbreviated FNAME was subjected to a principal components analysis (PCA) to assess construct validity, using data from all 210 subjects. We expected that FNAME items would be highly inter-correlated and that FN-N and FN-O items would represent two independent factors, as occupations are more easily recalled than names due to differences in storage mechanisms for each (McWeeny, Young, Hay, \& Ellis, 1987). The PCA revealed two underlying factors of the FNAME; face-name retrieval (ILN, CRN, CRN30) and faceoccupation retrieval (ILO, CRO, CRO30), explaining $93.1 \%$ of the variance $(76.2 \%, 17.1 \%$ respectively), consistent with prior findings (Rentz, et al., 2011). The Kaiser-Meyer-Oklin value of 0.82 and Bartlett's Test of Sphericity $(p<.001)$ supported the factorability of the correlation matrix. Given the outcome of the PCA, raw score summary composites were created for FN-N items (ILN, CRN, CRN30) and FN-O items (ILO, CRO, CRO30). To assess convergent validity, we examined the correlations between the FNAME and the SRT, a previously validated memory measure using Pearson's r. 
To assess test-retest reliability, Pearson's correlations were calculated between all the FNAME subtests at baseline and at follow-up for a subset of our total sample $(n=41)$. Of note, subjects who had progressed to a global CDR $\geq 0.5$ at follow-up were excluded from the test-retest analysis $(n=3)$. The test-retest time period was approximately one year (mean $=330$ days, $S . D .= \pm 118.8$ ), so as to limit practice effects, as well as replicate the clinical time frame in which the FNAME would be administered.

\section{Norms}

Finally, we calculated norms for the FNAME, using the entire sample of 210 subjects. FNAME summary scales were significantly correlated with age $(r=-0.27, p=0.000$, but not education or gender. Thus, we divided the group into tertiles by age. In addition to norms for the individual subtests of the FNAME (ILN, ILO, CRN, CRO, CRN30, CRO30), norms for the FN-N, FN-O, and FN-Total summary scales were computed.

\section{Results \\ Subject Characteristics}

The subject characteristics are provided in Table 2. The overall sample had an average age of $73.5 \pm 6.7$ years. There was no significant difference between the numbers of men and women in the sample. There was a significant gender difference on years of education, and performance on the SRT (Mann-Whitney U Test), but not on the FNAME subtests. Overall performance on the FNAME and SRT are reported in Table 2. (Table 2 about here).

\section{Validation}

Pairwise correlations of the FNAME subtests were high (range: 0.57-0.94) suggesting that items of the FNAME are closely related to each other (Table 3 about here). As mentioned, the PCA revealed two underlying factors of the FNAME; face-name (FN-N) and faceoccupation (FN-O) factors, consistent with the prior literature that demonstrates divergent performance on face-name pairs compared to face-occupation pairs (McWeeny, et al., 1987).

Evidence of convergent validity was found between the FNAME subscales (FN-N, FN-O) and SRT composite (see Table 4 about here). Test-retest reliability revealed significant correlations between FN-N, FN-O, FN-Total at baseline and follow-up, suggesting stability in performance over time (See Table 5 about here).

\section{Suggested Norms}

Age-adjusted norms were calculated for FN-N and FN-O raw summary scales, FN-Total summary scale, and for individual subtests of the FNAME. Neither gender nor education had a significant relationship on FNAME performance and was not considered in calculating the norms. The sample was divided into three age groups based on tertile (58-69, 70-76, 77-90) with roughly equivalent numbers of individuals in each group $(\mathrm{n}=72,69,69$ respectively) (See Table 6 about here). In general, performance on all summary scales and subtests of the FNAME declined with age (Figure 1 about here). Overall, performance on FN-O was superior to FN-N, confirmed by paired samples t-test. Furthermore, individuals who performed poorly on FN-O consistently performed poorly on the FN-N, however, a strong performance on the FN-O did not consistently track with performance on FN-N, suggesting that FN-N may be a particularly demanding memory task even in clinically normal older individuals (see Figure 2 about here). 


\section{Discussion}

The FNAME is a paired associative memory test developed to help distinguish between normal memory changes for age and the subtle memory changes that may be associated with biomarker evidence of preclinical AD. Exploration of the psychometric properties of the FNAME revealed a face-name factor (FN-N) and a face-occupation factor (FN-O) using factor analysis. Convergent validity was established with the SRT and test-retest reliability was found. Overall, FNAME performance declined with age and proved to be a highly challenging episodic memory test, particularly on FN-N items.

Identifying the subtle cognitive deficits characteristic of preclinical AD is not a new research endeavor. Longitudinal studies have compared performance on neuropsychological testing at baseline between older $\mathrm{CN}$ individuals and those who went on to develop symptoms of $\mathrm{AD}$ in order to infer cognitive performance characteristic of preclinical AD. In general, studies have typically found performance on tests of episodic memory, semantic knowledge, and executive functioning to discriminate between $\mathrm{CN}$ and preclinical $\mathrm{AD}$ individuals (Albert, Moss, Tanzi, \& Jones, 2001; Backman, Jones, Berger, Laukka, \& Small, 2005; Blacker et al., 2007; Clark et al., 2009; Collie \& Maruff, 2000). Cross-sectional studies comparing $\mathrm{CN}$ older individuals with and without risk factors for $\mathrm{AD}$ have also identified NP measures that may help to characterize preclinical AD, with results similar to longitudinal studies (Collie \& Maruff, 2000).

More recently, biomarker evidence has become a prerequisite for defining preclinical AD. A work group commissioned by the National Institute on Aging and the Alzheimer's Association, outlined criteria for preclinical AD that includes initial amyloid- $\beta$ accumulation, followed by evidence of synaptic dysfunction or early neurodegeneration (Sperling et al., 2011). Studies that have investigated cognitive performance of CN individuals with evidence of early neurodegeneration have shown a relationship between hippocampal atrophy and poor episodic memory (Jack, et al., 2008; Mormino, et al., 2009; Storandt, et al., 2009). In contrast, studies have not typically found a relationship between episodic memory and amyloid- $\beta$ accumulation in $\mathrm{CN}$ individuals (Aizenstein, et al., 2008; Jack, et al., 2008; Mormino, et al., 2009; Storandt, et al., 2009), aside from a study in which subjects had known genetic risk factors for AD (Pike et al., 2007).

Given that neuropsychological measures are generally designed to detect clinically significant cognitive impairment, it is unlikely the same tests sensitive to MCI and mild AD dementia will be useful in detecting the subtle changes associated with preclinical AD. Thus, the FNAME was developed to challenge $\mathrm{CN}$ individuals and to capture early subtle changes characteristic of preclinical AD. A paired associative learning test was chosen, as it is considered a particularly sensitive measure in detecting early changes due to AD (Blackwell et al., 2004; de Jager, Milwain, \& Budge, 2002; Fowler, et al., 2002; Parra, et al., 2010).

Previously, we found that FNAME scores were related to early amyloid- $\beta$ deposition (Rentz, et al., 2011) while another commonly used standardized memory test was not. The finding that FNAME performance was associated with biomarker evidence of early AD pathology was an exciting first step. The next critical steps will be to determine whether the FNAME can predict subjects who decline from those who remain clinically normal and whether the FNAME is associated with other biomarker evidence of AD. We are currently exploring these questions in a larger longitudinal sample who have biomarkers of amyloid- $\beta$ deposition and neurodegeneration. Additionally, we are adapting and validating shorter, easier versions of the FNAME against the current version so that it can be administered to individuals across the disease trajectory (i.e., $\mathrm{MCI}$ and $\mathrm{AD}$ ) within the context of a clinical 
trial. Taken together, we are hopeful that future studies will support the usefulness of the FNAME in predicting decline due to AD pathology.

The need for sophisticated and sensitive neuropsychological measures that can identify individuals in the earliest stages of $\mathrm{AD}$ is imperative as disease-modifying treatments will be most efficacious at this stage of the disease process. As a result, neuropsychologists have an important role to play in instrument development intended for future secondary prevention trials. Further development of cognitive tests based on neuroimaging studies will likely yield positive results. Several other fMRI studies have found differences in activation patterns for at-risk individuals, such as memory for famous faces (Seidenberg et al., 2009), verbal paired-associate learning (Han et al., 2007), novel discrimination memory (Johnson et al., 2006), and pattern separation (Yassa et al., 2010). Ultimately, we hope the FNAME and other newly developed neuropsychological measures will help inform and predict risk for cognitive decline in concert with biomarker evidence of the AD pathophysiological process.

\section{Acknowledgments}

The authors wish to thank M. Frey for helping to collect FNAME data, the investigators and staff of the Massachusetts Alzheimer's Disease Research Center and the individual research participants.

Funding

This work was supported by Alzheimer Association grants IIRG-08-90934 (D.R.), The Charles H. Farnsworth Trust (D.R.) and by National Institute on Aging grants P01-AG036694-01 (R.S.); P50-AG00513421 (R.S.); R01AG027435 (R.S.); R01-AG027435-S1 (R.S).

\section{References}

Aizenstein HJ, Nebes RD, Saxton JA, Price JC, Mathis CA, Tsopelas ND, et al. Frequent amyloid deposition without significant cognitive impairment among the elderly. Arch Neurol. 2008; 65(11): 1509-1517. doi: 65/11/1509 [pii] 10.1001/archneur.65.11.1509. [PubMed: 19001171]

Albert MS, Moss MB, Tanzi R, Jones K. Preclinical prediction of AD using neuropsychological tests. J Int Neuropsychol Soc. 2001; 7(5):631-639. [PubMed: 11459114]

Backman L, Jones S, Berger AK, Laukka EJ, Small BJ. Cognitive impairment in preclinical Alzheimer's disease: a meta-analysis. Neuropsychology. 2005; 19(4):520-531. doi: 2005-08223-013 [pii] 10.1037/0894-4105.19.4.520. [PubMed: 16060827]

Blacker D, Lee H, Muzikansky A, Martin EC, Tanzi R, McArdle JJ, et al. Neuropsychological measures in normal individuals that predict subsequent cognitive decline. Arch Neurol. 2007; 64(6): 862-871. doi: 64/6/862 [pii] 10.1001/archneur.64.6.862. [PubMed: 17562935]

Blackwell AD, Sahakian BJ, Vesey R, Semple JM, Robbins TW, Hodges JR. Detecting dementia: novel neuropsychological markers of preclinical Alzheimer's disease. Dement Geriatr Cogn Disord. 2004; 17(1-2):42-48. doi: 10.1159/000074081 DEM20040171_2042 [pii]. [PubMed: 14560064]

Celone KA, Calhoun VD, Dickerson BC, Atri A, Chua EF, Miller SL, et al. Alterations in memory networks in mild cognitive impairment and Alzheimer's disease: an independent component analysis. J Neurosci. 2006; 26(40):10222-10231. doi: 26/40/10222 [pii] 10.1523/JNEUROSCI. 2250-06.2006. [PubMed: 17021177]

Clark LJ, Gatz M, Zheng L, Chen YL, McCleary C, Mack WJ. Longitudinal verbal fluency in normal aging, preclinical, and prevalent Alzheimer's disease. Am J Alzheimers Dis Other Demen. 2009; 24(6):461-468. doi: 1533317509345154 [pii] 10.1177/1533317509345154. [PubMed: 19759254]

Collie A, Maruff P. The neuropsychology of preclinical Alzheimer's disease and mild cognitive impairment. Neurosci Biobehav Rev. 2000; 24(3):365-374. [PubMed: 10781696]

de Jager CA, Milwain E, Budge M. Early detection of isolated memory deficits in the elderly: the need for more sensitive neuropsychological tests. Psychol Med. 2002; 32(3):483-491. [PubMed: 11989993] 
Folstein MF, Folstein SE, McHugh PR. Mini-mental state”. A practical method for grading the cognitive state of patients for the clinician. J Psychiatr Res. 1975; 12(3):189-198. doi: 0022-3956(75)90026-6 [pii]. [PubMed: 1202204]

Fowler KS, Saling MM, Conway EL, Semple JM, Louis WJ. Paired associate performance in the early detection of DAT. J Int Neuropsychol Soc. 2002; 8(1):58-71. [PubMed: 11843075]

Grober E, Merling A, Heimlich T, Lipton RB. Free and cued selective reminding and selective reminding in the elderly. J Clin Exp Neuropsychol. 1997; 19(5):643-654. [PubMed: 9408795]

Han SD, Houston WS, Jak AJ, Eyler LT, Nagel BJ, Fleisher AS, et al. Verbal paired-associate learning by APOE genotype in non-demented older adults: fMRI evidence of a right hemispheric compensatory response. Neurobiol Aging. 2007; 28(2):238-247. doi: S0197-4580(05)00452-5 [pii] 10.1016/j.neurobiolaging.2005.12.013. [PubMed: 16434125]

Jack CR Jr. Lowe VJ, Senjem ML, Weigand SD, Kemp BJ, Shiung MM, et al. 11C PiB and structural MRI provide complementary information in imaging of Alzheimer's disease and amnestic mild cognitive impairment. Brain. 2008; 131(Pt 3):665-680. doi: awm336 [pii] 10.1093/brain/awm336. [PubMed: 18263627]

Johnson SC, Schmitz TW, Trivedi MA, Ries ML, Torgerson BM, Carlsson CM, et al. The influence of Alzheimer disease family history and apolipoprotein E epsilon 4 on mesial temporal lobe activation. J Neurosci. 2006; 26(22):6069-6076. doi: 26/22/6069 [pii] 10.1523/JNEUROSCI. 0959-06.2006. [PubMed: 16738250]

Lindeboom J, Schmand B, Tulner L, Walstra G, Jonker C. Visual association test to detect early dementia of the Alzheimer type. J Neurol Neurosurg Psychiatry. 2002; 73(2):126-133. [PubMed: 12122168]

Masur DM, Fuld PA, Blau AD, Thal LJ, Levin HS, Aronson MK. Distinguishing normal and demented elderly with the selective reminding test. J Clin Exp Neuropsychol. 1989; 11(5):615630. [PubMed: 2808653]

McWeeny KH, Young AW, Hay DC, Ellis AW. Putting names to faces. British Journal of Psychology. 1987; 78:143-149.

Miller SL, Celone K, DePeau K, Diamond E, Dickerson BC, Rentz D, et al. Age-related memory impairment associated with loss of parietal deactivation but preserved hippocampal activation. Proc Natl Acad Sci U S A. 2008; 105(6):2181-2186. doi: 0706818105 [pii] 10.1073/pnas. 0706818105. [PubMed: 18238903]

Mormino EC, Kluth JT, Madison CM, Rabinovici GD, Baker SL, Miller BL, et al. Episodic memory loss is related to hippocampal-mediated beta-amyloid deposition in elderly subjects. Brain. 2009; 132(Pt 5):1310-1323. doi: awn320 [pii] 10.1093/brain/awn320. [PubMed: 19042931]

Morris JC. The Clinical Dementia Rating (CDR): current version and scoring rules. Neurology. 1993; 43(11):2412-2414. [PubMed: 8232972]

Parra MA, Abrahams S, Logie RH, Mendez LG, Lopera F, Della Sala S. Visual short-term memory binding deficits in familial Alzheimer's disease. Brain. 2010; 133(9):2702-2713. doi: awq148 [pii] 10.1093/brain/awq148. [PubMed: 20624814]

Pike KE, Savage G, Villemagne VL, Ng S, Moss SA, Maruff P, et al. Beta-amyloid imaging and memory in non-demented individuals: evidence for preclinical Alzheimer's disease. Brain. 2007; 130(Pt 11):2837-2844. doi: awm238 [pii] 10.1093/brain/awm238. [PubMed: 17928318]

Quiroz YT, Budson AE, Celone K, Ruiz A, Newmark R, Castrillon G, et al. Hippocampal hyperactivation in presymptomatic familial Alzheimer's disease. Ann Neurol. 2010; 68(6):865875. doi: 10.1002/ana.22105. [PubMed: 21194156]

Rentz DM, Amariglio RE, Becker JA, Frey M, Olson LE, Frishe K, et al. Face-name associative memory performance is related to amyloid burden in normal elderly. Neuropsychologia. 2011; 49(9):2776-2783. doi: S0028-3932(11)00280-6 [pii] 10.1016/j.neuropsychologia.2011.06.006. [PubMed: 21689670]

Rentz DM, Locascio JJ, Becker JA, Moran EK, Eng E, Buckner RL, et al. Cognition, reserve, and amyloid deposition in normal aging. Ann Neurol. 2010; 67(3):353-364. doi: 10.1002/ana.21904. [PubMed: 20373347] 
Seidenberg M, Guidotti L, Nielson KA, Woodard JL, Durgerian S, Antuono P, et al. Semantic memory activation in individuals at risk for developing Alzheimer disease. Neurology. 2009; 73(8):612620. doi: 73/8/612 [pii] 10.1212/WNL.0b013e3181b389ad. [PubMed: 19704080]

Sperling RA, Aisen PS, Beckett LA, Bennett DA, Craft S, Fagan AM, et al. Toward defining the preclinical stages of Alzheimer's disease: Recommendations from the National Institute on AgingAlzheimer's Association workgroups on diagnostic guidelines for Alzheimer's disease. Alzheimers Dement. 2011; 7(3):280-292. doi: S1552-5260(11)00099-9 [pii] 10.1016/j.jalz. 2011.03.003. [PubMed: 21514248]

Sperling RA, Bates JF, Chua EF, Cocchiarella AJ, Rentz DM, Rosen BR, et al. fMRI studies of associative encoding in young and elderly controls and mild Alzheimer's disease. J Neurol Neurosurg Psychiatry. 2003; 74(1):44-50. [PubMed: 12486265]

Sperling RA, Laviolette PS, O’Keefe K, O’Brien J, Rentz DM, Pihlajamaki M, et al. Amyloid deposition is associated with impaired default network function in older persons without dementia. Neuron. 2009; 63(2):178-188. doi: S0896-6273(09)00505-4 [pii] 10.1016/j.neuron.2009.07.003. [PubMed: 19640477]

Storandt M, Mintun MA, Head D, Morris JC. Cognitive decline and brain volume loss as signatures of cerebral amyloid-beta peptide deposition identified with Pittsburg compound B: cognitive decline associated with Abeta deposition. Arch Neurol. 2009; 66(12):1476-1481. [PubMed: 20008651]

Werheid K, Clare L. Are faces special in Alzheimer's disease? Cognitive conceptualisation, neural correlates, and diagnostic relevance of impaired memory for faces and names. Cortex. 2007; 43(7): 898-906. [PubMed: 17941348]

Yassa MA, Lacy JW, Stark SM, Albert MS, Gallagher M, Stark CE. Pattern separation deficits associated with increased hippocampal CA3 and dentate gyrus activity in nondemented older adults. Hippocampus. 2010 doi: 10.1002/hipo.20808.

Yesavage JA, Brink TL, Rose TL, Lum O, Huang V, Adey M, et al. Development and validation of a geriatric depression screening scale. Psychiatry Res. 1983; 17(1):37-49. 


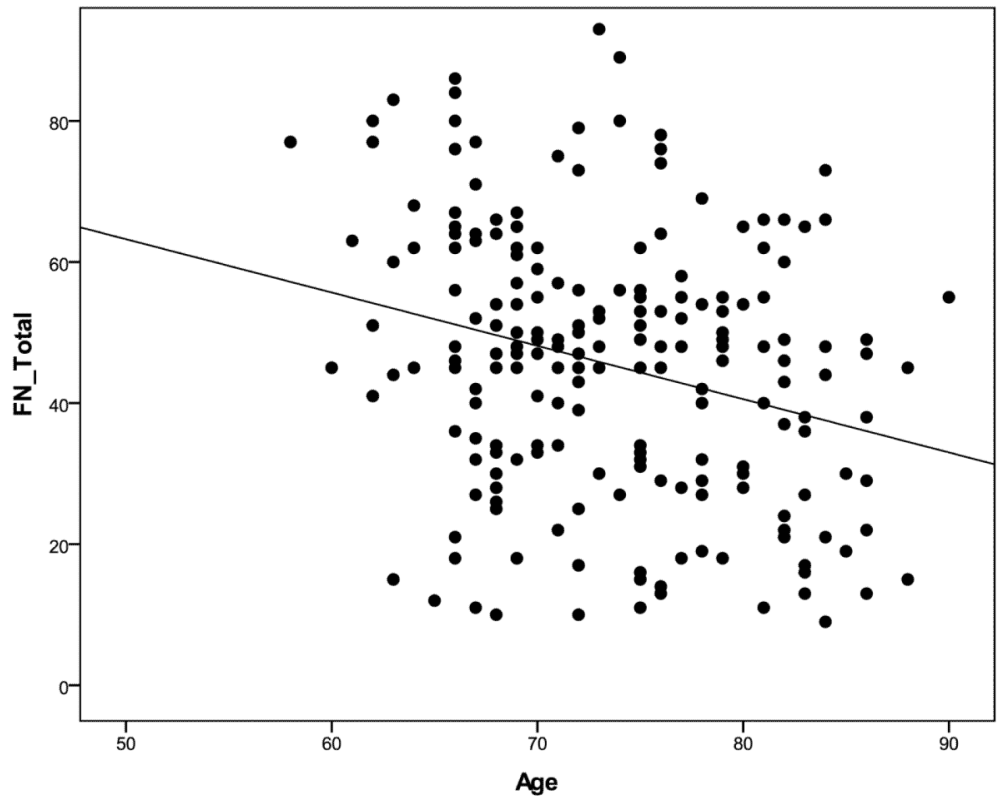

Figure 1.

Scatter plot of age and FNAME total raw score summary scale. Performance on the FNAME declines with age. 


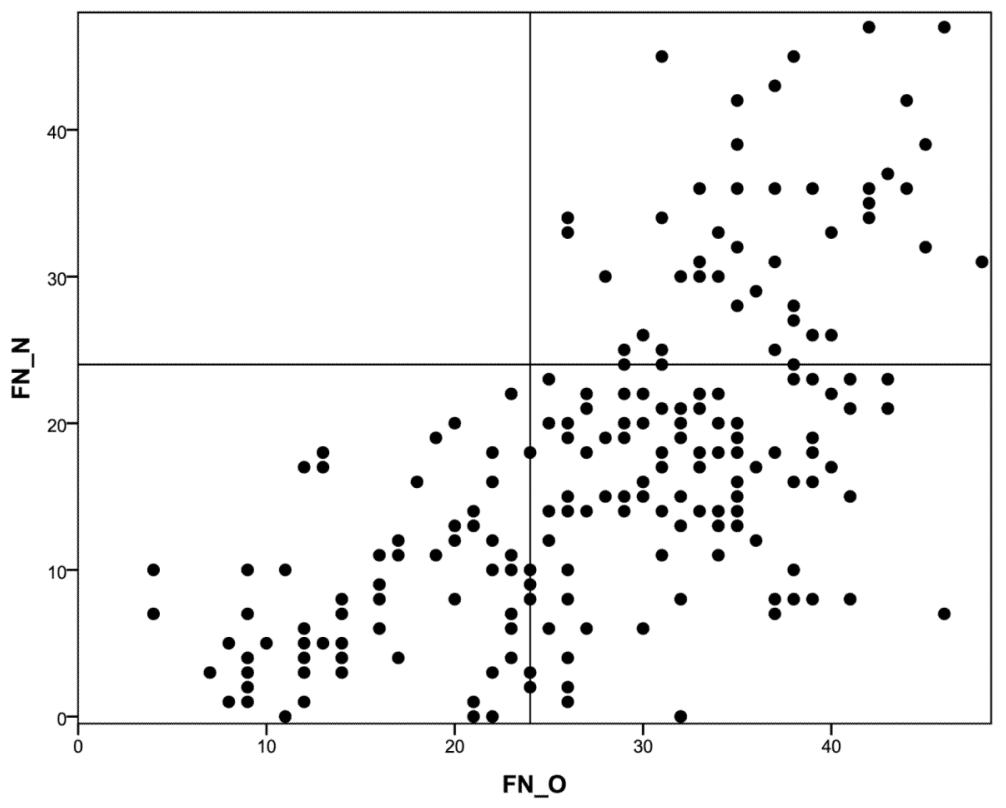

Figure 2.

Poor performance on $\mathrm{FN}-\mathrm{N}$ may result in either a high or low performance on $\mathrm{FN}-\mathrm{O}$. By contrast, strong performance on FN-N corresponds with strong performance on FN-O. 


\section{Table 1}

Independent samples t-tests, mean scores, and standard deviations of the Cued Recall trials between subjects with and without free recall trials.

\begin{tabular}{|c|c|c|c|}
\hline & \multicolumn{2}{|c|}{ Mean (SD) } & p-value \\
\hline & $\begin{array}{c}1 \\
(\mathrm{n}=148)\end{array}$ & $\begin{array}{c}2 \\
(\mathrm{n}=62)\end{array}$ & \\
\hline CRN & $5.32(3.8)$ & $5.10(3.4)$ & 0.69 \\
\hline CRO & $9.44(3.4)$ & $9.18(3.5)$ & 0.62 \\
\hline CRN30 & $5.35(4.1)$ & $5.1(3.4)$ & 0.64 \\
\hline CRO30 & $9.14(3.5)$ & $8.74(3.2)$ & 0.44 \\
\hline
\end{tabular}

Significance level set at $\mathrm{p} \leq 0.05$.

$\mathrm{M}=$ mean scores, $\mathrm{SD}=$ standard deviation, $\mathrm{CRN}=$ cued recall for names, $\mathrm{CRO}=$ cued recall for occupations, $\mathrm{CRN} 30=$ cued recall for names after a 30 minute delay, $\mathrm{CRO} 30=$ cued recall for occupations after a 30 minute delay. 
Table 2

Demographic characteristics of subjects and performance on the Selective Reminding Test (SRT) across the sample.

\begin{tabular}{lcc}
\hline $\boldsymbol{n = 2 1 0}$ & $\mathbf{M}$ & $\mathbf{S D}$ \\
\hline Age, years & 73.57 & 6.73 \\
Female, \% & 53.3 & \\
Education, years & 16.15 & 2.88 \\
MMSE & 29.19 & 0.81 \\
GDS & 2.95 & 2.86 \\
TR & 45.01 & 9.04 \\
DR & 6.06 & 2.91 \\
DR30 & 6.64 & 3.24 \\
LTS & 33.48 & 14.03 \\
LTR & 30.46 & 13.78 \\
CR & 21.69 & 11.57 \\
CLTR & 21.28 & 14.19 \\
\hline
\end{tabular}

$\mathrm{M}=$ mean score, $\mathrm{SD}=$ standard deviation, $\mathrm{MMSE}=$ Mini Mental Status Exam, GDS = 30-item Geriatric Depression Scale. $\mathrm{SRT}$ variables; TR = total recall, $\mathrm{DR}=$ delayed recall at 10 -minutes, $\mathrm{DR} 30=$ delayed recall at 30 minutes, $\mathrm{LTR}=$ long-term retrieval, $\mathrm{LTS}=$ long-term store, $\mathrm{CR}=$ continuous retrieval, CLTR= continuous long-term retrieval. 


\begin{tabular}{|c|c|c|c|c|c|}
\hline 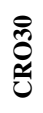 & $\begin{array}{c}* \\
* \\
\infty \\
n \\
0 \\
0\end{array}$ & 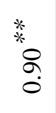 & $\begin{array}{l}* \\
\text { * } \\
\text { in }\end{array}$ & * & 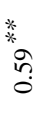 \\
\hline 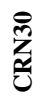 & 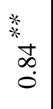 & $\begin{array}{l}\text { * } \\
\text { *o } \\
\text { : } \\
0\end{array}$ & * & * & \\
\hline \&্ & 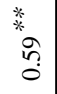 & $\begin{array}{l}* \\
\text { * } \\
\text { Oे }\end{array}$ & 茪 & & \\
\hline Z & $\begin{array}{l}* \\
* \\
\infty \\
\infty \\
0\end{array}$ & $\begin{array}{l}* \\
* \\
\stackrel{*}{0} \\
0\end{array}$ & & & \\
\hline 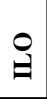 & 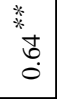 & & & & \\
\hline 桼 & & & & & \\
\hline & Z & $\stackrel{\circ}{9}$ & Z & \&ै & 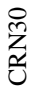 \\
\hline
\end{tabular}




\section{Table 4}

Correlations of z-score composites of FNAME subscales and SRT to determine convergent validity.

\begin{tabular}{|c|c|}
\hline & SRT \\
\hline FN-N & $0.54(0.00)^{*}$ \\
\hline FN-O & $0.42(0.00)^{*}$ \\
\hline
\end{tabular}

SRT variables included: long-term retrieval (LTR), long-term store (LTS), continuous retrieval (CR), continuous long-term retrieval (CLTR), total recall (TR), delayed recall at 10-minutes (DR), and delayed recall at 30 minutes (DR30). FNAME FN-O subtests including initial learning for occupations (ILO), immediate cued recall for occupations (CRO), and delayed cued recall for occupations (CRO30).

Significance level set at $\mathrm{p} \leq 0.001$. 
Table 5

Test-Retest correlations.

\begin{tabular}{|l|l|l|l|}
\hline & FN-N2 & FN-O2 & FN-Total2 \\
\hline FN-N1 & $0.61(0.000)^{*}$ & & \\
\hline FN-O1 & & $0.49(0.004)^{*}$ & \\
\hline FN-Total1 & & & $0.622(0.000)^{*}$ \\
\hline
\end{tabular}

FNAME FN-N1 subtests included initial learning for names (ILN), immediate cued recall for names (CRN), delayed cued recall for names (CRN30) at Year 1. FNAME FN-O1 subtests including initial learning for occupations (ILO), immediate cued recall for occupations (CRO), and delayed cued recall for occupations (CRO30) at Year 1. FNAME FN-N2 subtests included initial learning for names (ILN), immediate cued recall for names (CRN), delayed cued recall for names (CRN30) at Year 2. FNAME FN-O1 subtests including initial learning for occupations (ILO), immediate cued recall for occupations (CRO), and delayed cued recall for occupations (CRO30) at Year 2.

Significance level set at $\mathrm{p} \leq 0.005$. 
岂 $\frac{0}{0}$

?

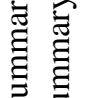

Z Z

斊空

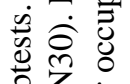

卷㐘

펑

$\sum$ 这

双 夛

สิ

잉

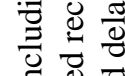

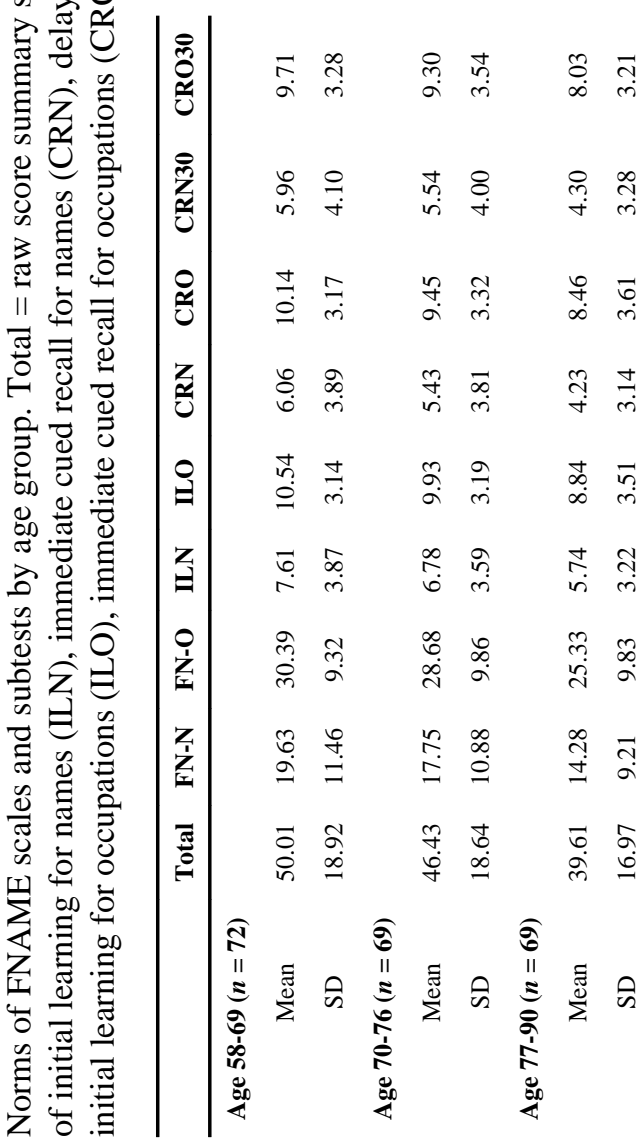

